\title{
Preface to the Dust Topical Collection
}

\author{
Domenico M. Doronzo ${ }^{1,2}$ • Ali Al-Dousari ${ }^{3}$ - Arnau Folch ${ }^{4}$. \\ Pavla Dagsson-Waldhauserova ${ }^{5}$
}

Published online: 21 May 2016

(C) Saudi Society for Geosciences 2016

The amount of dust is continuously varying, and this very much is because the planet Earth is alive. Dust is more than a microscopic object, instead it is the product of a process, and there are several processes occurring on Earth, from environmental to anthropogenic. Dust has inspired many artists in songs (e.g., "Cities in Dust" by Siouxie and The Banshees, and "The Great Dust Storm" by Woody Guthrie) and movies (e.g., "Mission Impossible 4" by Brad Bird, and "Pompeii" by Paul Anderson). Micrometric solid particles can generally be considered as dust, and this broad definition gives an idea of how dust can globally impact the Earth. As examples, dust from the Sahara Desert can easily reach the Amazonia Forest during big storms, and fine volcanic ash injected at stratospheric levels can tour all around the planet. In 2011, a North African dust outbreak affected Europe, from the Iberian Peninsula to Great Britain and Scandinavia. Dust is part of the ecological systems on

This article is part of the Topical Collection on DUST

Domenico M. Doronzo

domenico-doronzo@libero.it

Polytechnic School of Bari, Bari, Italy

2 National Autonomous University of Mexico, Queretaro, Mexico

Kuwait Institute for Scientific Research, Kuwait City, Kuwait

4 Barcelona Supercomputing Center, Barcelona, Spain

5 University of Iceland, Reykjavik, Iceland
Earth, and the topic was recently discussed during the DUST2014 Conference held in Castellaneta Marina, Italy in June 2014, and chaired by Prof. Saverio Fiore from CNR, Italy. Following the great success of that international conference on atmospheric dust, we decided to contribute with the present Dust Topical Collection in the Arabian Journal of Geosciences, edited by Springer. This special volume is unique in collecting 23 peer-reviewed original papers on dust research, and in presenting the results from several different perspectives and approaches in geosciences: environmental, ecological, atmospheric, volcanic, aerosol, meteorological, industrial, powder technology, urban, chemical, health, legislative, botanic, and sport. The scientific interest to conjugate all these aspects in the same volume extends our motivation emerged from the DUST2014 Conference, and also supplements the need to fully address multiple investigation approaches (experimental, mathematical, laboratory, field observation, satellite image analysis) and applications (environmental, anthropogenic), which complement each other. We welcome in this volume contributions received from all five continents, with a more devotion to the Middle East and Euro-Mediterranean Area, which are particularly sensitive to silica dust from desert. We are confident that this topical collection will help updating the state-of-the-art on dust and its positive and negative impact on the environment, people, socio-economic activities, and industrial processes. We acknowledge in advance all readers, and hope that this volume will open new collaborative directions on dust research in the future. 